\title{
INFLUENCE OF LASER SHOCK PEENING ON RESIDUAL STRESS AND FATIGUE LIFE OF STAINLESS STEELS
}

\author{
1,2Zbyněk ŠPIRIT, ${ }^{3}$ Jan KAUFMAN, ${ }^{1}$ Josef STREJCIUS, ${ }^{1}$ Michal CHOCHOLOUŠEK, ${ }^{1}$ Josef KOTT \\ ${ }^{1}$ Centrum vyzkumu Rez s.r.o., Pilsen, Czech Republic, EU; zbynek.spirit@cvrez.cz \\ ${ }^{2}$ Department of Material Science and Technology, University of West Bohemia, Pilsen, Czech Republic, EU \\ ${ }^{3}$ Hilase, Institute of Physics of the ASCR, v.v.i., Prague, Czech Republic
}

https://doi.org/10.37904/metal.2019.887

\section{Abstract}

This paper shows influence of Laser Shock Peening (LSP) on Residual stress (RS) and Fatigue life of stainless steels. LSP is an innovative surface treatment technique for strengthening metallic materials. The principle of LSP is based on conversion of laser energy into a shock wave that results in material plastic deformation and redistribution of RS. The aim of the RS redistribution is to move the compressive RS to maximally stressed area in component. Suitable RS redistribution in component, can lead to increase of component fatigue life. The paper is focused on the RS change and fatigue life after LSP treatment. The tested material was austenitic stainless steel which is used in nuclear industry. The depth profile of RS was measured by X-ray diffraction (XRD) and fatigue life was examined through the three-point bend fatigue test.

Keywords: Laser Shock Peening, residual stress, fatigue life, stainless steel

\section{INTRODUCTION}

This paper follows after the paper "Effect of Laser Shock Peening on Fatigue life of Austenitic stainless steels", which was focused on increased Fatigue life after LSP treatment. This paper is focused on optimization of pattern sequences for fatigue life increase on the Three Point Bending (3PB) specimens. The principle of LSP is based on conversion of laser energy into a shock wave that results in material plastic deformation and redistribution of residual stresses. When the high energy laser pulses of short nanosecond durations focus on a water immersed metal material, the top surface (sacrificial layer) absorbs the laser energy and evaporates instantaneously through ablative interaction, as shown in Figure 1. The resulting high-density vapor is immediately ionized (multiphoton ionization and avalanche ionization) and forms a plasma plume which absorbs the rest of the laser pulse via the inverse Bremsstrahlung mechanism, the absorption of high-intensity radiation by electrons in the field of nuclei [1-5]. High pressure of the expanding plasma generates a shock wave, which impinges on the surface of the metal material with an intensity of several GPa, far exceeding the yield strength of the metal. The shock wave propagates into the metal interior and loses energy as it creates a permanent strain on the metal material. The permanent strain remains after the shock wave passage. The strained region is subsequently constrained with surrounded metal material as a reaction to elastic strain, thus forming a compressive residual stress on the metal surface $[4,5,6]$.

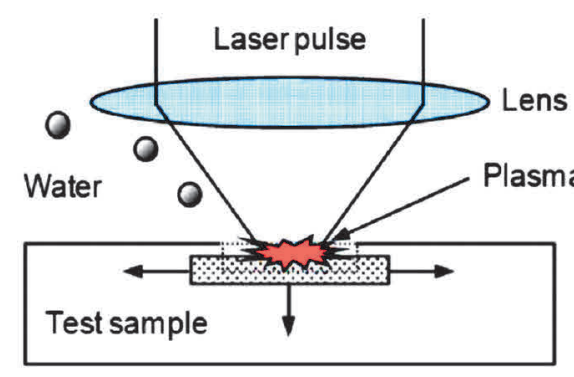

During laser irradiation

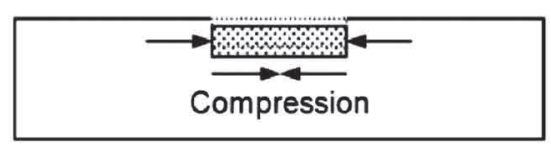

After laser irradiation

Figure 1 Principle of LSP process [4] 


\section{MATERIAL}

The testing material was austenitic stainless steel 08CH18N10T for nuclear industry with certificate EN 10204/3.1. Chemical composition and basic mechanical properties are in Table 1 and Table 2. Specimens for High Cycle Fatigue (HCF) 3PB test were manufactured from the material in accordance with the drawing design in Figure 2 [4].

Table 1 Chemical composition of 08CH18N10T

\begin{tabular}{|c|c|c|c|c|c|c|c|c|c|c|c|}
\hline Material & $\begin{array}{c}\mathbf{F e} \\
(\mathbf{w t} \%)\end{array}$ & $\begin{array}{c}\mathbf{C} \\
(\mathbf{w t} \%)\end{array}$ & $\begin{array}{c}\mathbf{M n} \\
(\mathbf{w t} \%)\end{array}$ & $\begin{array}{c}\mathbf{S i} \\
(\mathbf{w t} \%)\end{array}$ & $\begin{array}{c}\mathbf{P} \\
(\mathbf{w t} \%)\end{array}$ & $\begin{array}{c}\mathbf{S} \\
(\mathbf{w t} \%)\end{array}$ & $\begin{array}{c}\mathbf{C r} \\
(\mathbf{w t} \%)\end{array}$ & $\begin{array}{c}\mathbf{N i} \\
(\mathbf{w t} \%)\end{array}$ & $\begin{array}{c}\mathbf{C u} \\
(\mathbf{w t} \%)\end{array}$ & $\begin{array}{c}\mathbf{M o} \\
(\mathbf{w t} \%)\end{array}$ & $\begin{array}{c}\mathrm{Ti} \\
(\mathbf{w t} \%)\end{array}$ \\
\hline 08CH18N10T & - & 0.05 & 1.68 & 0.57 & 0.02 & 0.001 & 17.5 & 9.9 & 0.06 & 0.06 & 0.47 \\
\hline
\end{tabular}

Table 2 Basic mechanical properties of 08CH18N10T: Yield Strength (YS), Ultimate Tensile Strength (UTS)

\begin{tabular}{|c|c|c|c|c|}
\hline Material & Temperature $\left({ }^{\circ} \mathrm{C}\right)$ & YS (MPa) & UTS (MPa) & Elongation (\%) \\
\hline 08CH18N10T & 30 & 248 & 565 & 54.5 \\
\hline
\end{tabular}
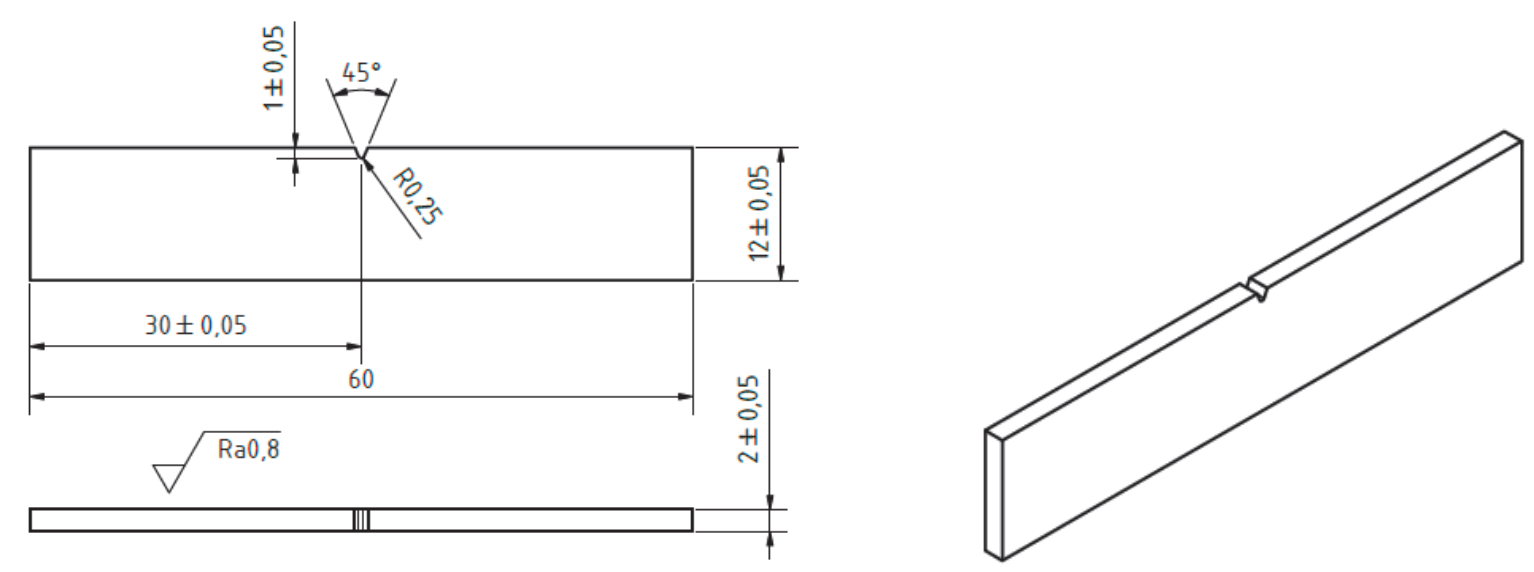

Figure 2 Specimen drawing for HCF three-point bending test

\section{EXPERIMENTAL PROCEDURE}

The aim of experiment is optimization of fatigue life on unpeened specimens with LSP treatment specimens. The specimens were manufactured by Electric Discharge Machining (EDM) with $1 \mathrm{~mm}$ depth notch, as shown in Figure 2. The specimens sides were gridding to roughness Ra $0.8 \mu \mathrm{m}$. After manufacturing specimens, RS was measured by XRD machine in three areas below the notch (see Figure 4). These areas are significant for propagating fatigue crack. The goal of LSP sequence was to increase the compressive RS at the notch (Figure 4, area 1). The specimen surfaces were treated from both sides using L2 system - BIVOJ (HiLASE Centrum, CZ) [7] with a wavelength of $1030 \mathrm{~nm}$, pulse duration $10 \mathrm{~ns}$, maximum energy $100 \mathrm{~J}$ and frequency $10 \mathrm{~Hz}$. The laser parameters of surface treatment are shown in Table 3. The dimension of LSP patch was $8 \mathrm{x}$ $8 \mathrm{~mm}$ (see Figure 3). The pattern strategy [8] - sequence of the LSP is in the Figure 5. The first shots in first sequence are red colour and every shots start from left side to right direction (see Figure 5). The next shots in the second row are blue colour and sequences are shifted $1 \mathrm{~mm}$ up. The last shots in the eighth row are green.

Table 3 Basic mechanical properties of 08CH18N10T [4]

\begin{tabular}{|c|c|c|c|c|c|c|}
\hline $\begin{array}{l}\text { Energy in } \\
\text { puls }(\mathrm{J})\end{array}$ & $\begin{array}{c}\text { Beam diameter } \\
(\mathrm{mm})\end{array}$ & $\begin{array}{c}\text { Power density } \\
\left(\mathrm{GW} / \mathrm{cm}^{2}\right)\end{array}$ & $\begin{array}{c}\text { Overlap in line } \\
(\%)\end{array}$ & Tape & Sequence/layer & $\begin{array}{c}\text { Number of } \\
\text { passes }\end{array}$ \\
\hline 2.5 & 2 & 6.25 & 50 & Vinyl & 4 & 1 \\
\hline
\end{tabular}




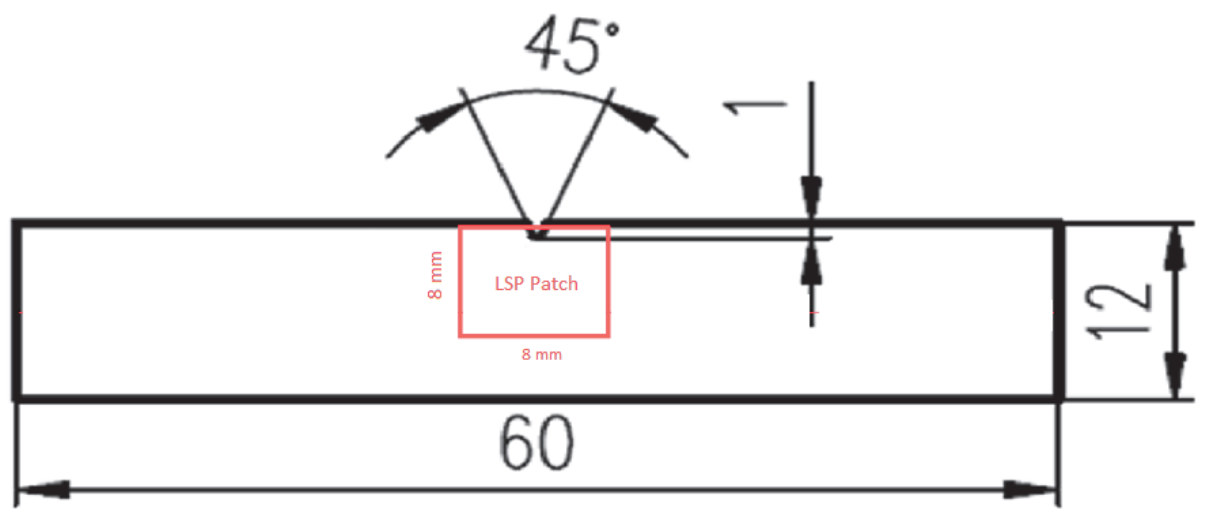

Figure 3 Position of LSP patch

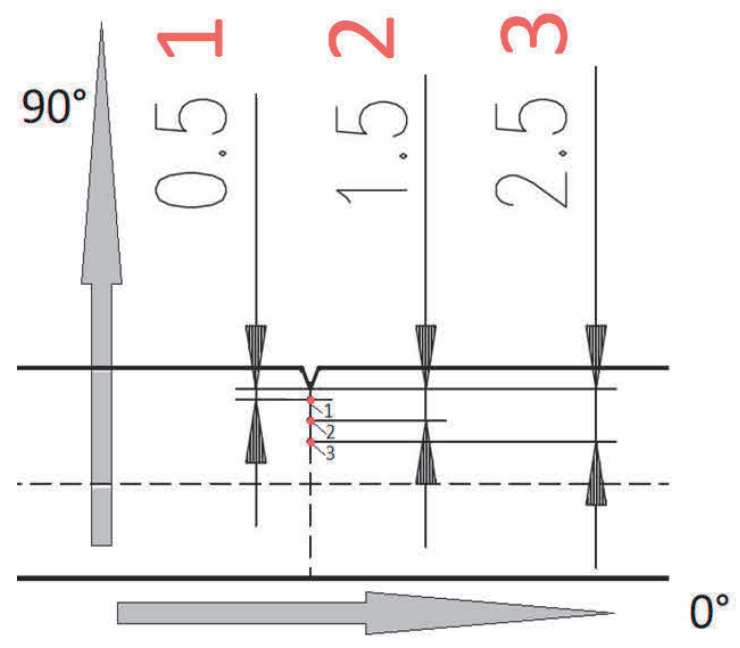

Figure 4 Location of RS measured areas

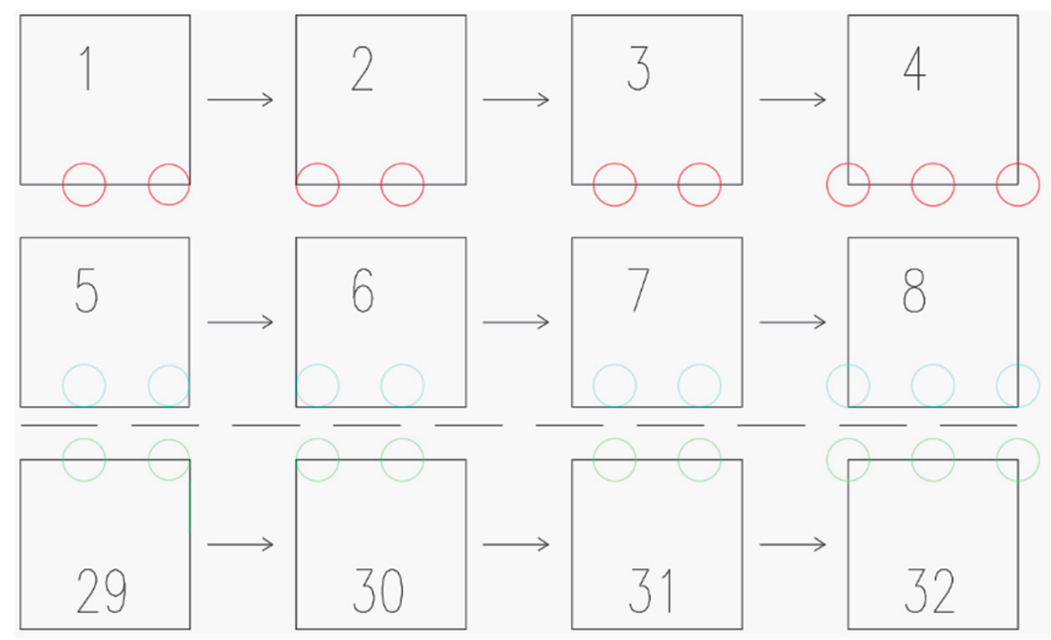

Figure 5 Laser shot strategy in sequences in patch area

Fatigue test were performed in load control on Electromagnetic pulsator for HCF testing - RUMUL. Table 4 shows the testing parameters. RS were measured on XRD machines RIGAKU AutoMATE II with parameters tube - $\mathrm{Cr} / \mathrm{K}$ alpha $1 / 40 \mathrm{kV} / 40 \mathrm{~mA}$, peak angle - $129.15 \mathrm{deg}$, collimator - $2 \mathrm{~mm}$, meas. method - iso-inclination, Psi0, osciallate -5 deg. 
Table 4 HCF parameters

\begin{tabular}{|c|c|c|c|c|c|}
\hline Load & Support span $\mathbf{( m m )}$ & Stress ratio & Frequency $\mathbf{( H z )}$ & $\begin{array}{c}\text { Test stop at delta frequency } \\
\mathbf{( H z )}\end{array}$ & $\begin{array}{c}\text { Test } \\
\text { temperature }\left({ }^{\circ} \mathbf{C}\right)\end{array}$ \\
\hline 3PB & 40 & 0.1 & $90-92$ & 20 & 22 \\
\hline
\end{tabular}

\section{RESULTS}

The results of RS measuring are summarized in Figure 6. The measured values show increase by more than $220 \mathrm{MPa}$ of compressive RS nearby the notch in area 1 after LSP treatment compared to unpeened material. The RS values after LSP treatment in the areas 2 and 3 are only slightly higher than compressive RS of unpeened material. The measurement of the RS depth profile is in progress.

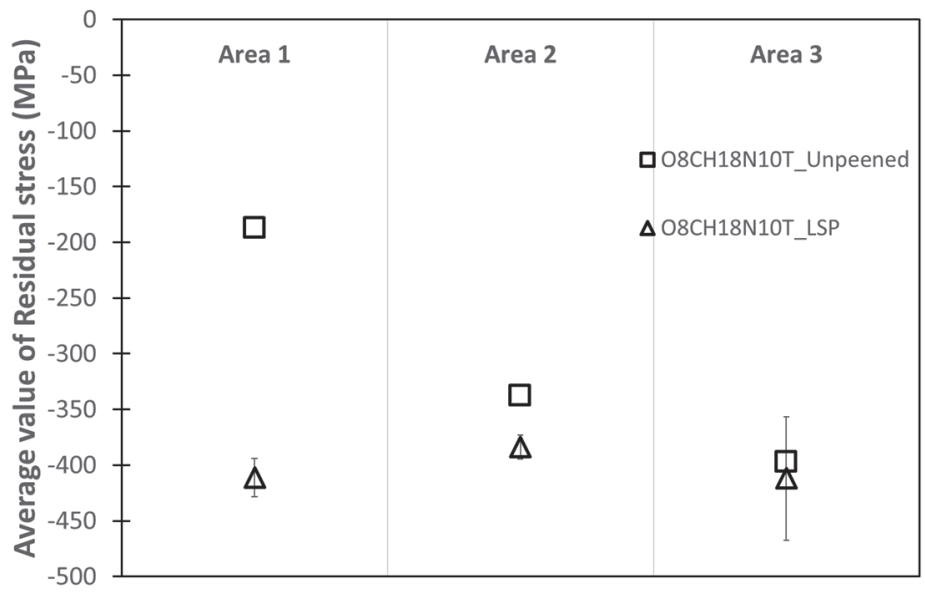

Figure 6 RS value before and after LSP treatment

The results of fatigue life of LSP and unpeened specimens are summarized in Figure 7. The value of fatigue life cycles was set to the value of delta frequency decreased by $20 \mathrm{~Hz}$ (approx. the crack propagation to the middle of the specimen). The fatigue life $\left(10^{7}\right.$ cycles) of peened specimens was evaluated at $\sigma_{\max } 280 \mathrm{MPa}$ and of unpeened specimens at $180 \mathrm{MPa}$. The peened material achieved higher value of fatigue life cycles about more than $55 \%$ than unpeened specimens.

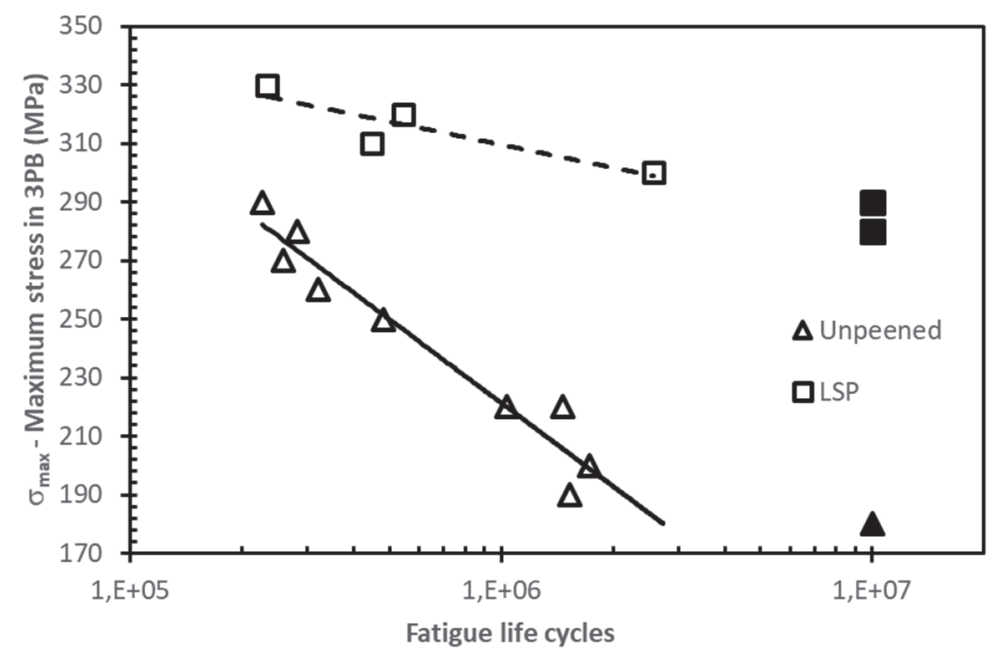

Figure 7 Effect of LSP treatment on 3PB fatigue life of $08 \mathrm{CH} 18 \mathrm{~N} 10 \mathrm{~T}$ 


\section{CONCLUSION}

The presented paper shows results of LSP process optimization for improving the HCF performance on 3PB specimens. The peened specimens had more than $55 \%$ higher fatigue life than unpeened specimens. The maximum compressive stress was measured nearby the notch with value $-411 \pm 17 \mathrm{MPa}$ in the peened specimens and $-187 \pm 24 \mathrm{MPa}$ on the unpeened specimens in the same area. It follows from the presented results that the correctly chosen shots strategy has a fundamental influence on the distribution of residual stress and thus also on the increase in fatigue life.

\section{ACKNOWLEDGEMENTS}

The presented work was financially supported by the Ministry of Education, Youth and Sport Czech Republic - project LQ1603 Research for SUSEN. This work has been realized within the SUSEN Project (established in the framework of the European Regional Development Fund (ERDF) in project CZ.1.05/2.1.00/03.0108 and of the European Structural and Investment Funds (ESIF) in the project CZ.02.1.01/0.0/0.0/15_008/0000293).

\section{REFERENCES}

[1] CHAMPAIGNE, J. History of Shot Peening Specifications. In The ninth International Conference on Shot Peening. Paris: pp 12-16, 2005, ISBN 2907669370

[2] DING, K and Ye L. Laser shock peening, Performance and process simulation, Woodhead Publishing on behalf of The Institute of Materials, Minerals and Mining, Cambridge England, 2006. P. 63.

[3] CLAURER, A.H, GREGORY, J.K, RACK, H.J and EYLON, D. Laser shock peening for fatigue resistance. Proceedings of Surface Performance of Titanium. Cincinnati:1997, pp. 217-30.

[4] SPIRIT, Z., BRAJER, J., KAUFMAN, J., CHOCHOLOUSEK, M., BOHM, M., KOTT, J. and STREJCIUS, J. Effect of Laser Shock Peening on Fatigue life of Austenitic stainless steels. IOP Conference Series: Materials Science and Engineering 461:012084. Plzen: 2018.

[5] Materials Reliability Program: Technical Basis for Primary Water Stress Corrosion Cracking Mitigation by Surface Stress Improvement (MRP-267, Revision 2), EPRI Project, July 2016

[6] BRICÍN, D., PRŮCHA, V., KŘíž A. Abraded Surface Properties of Sintered Carbide Specimens Before and After Deposition of a Thin Layer Using PVD. Proceedings of the 28th DAAAM International Symposium. Vienna: DAAAM International, 2017. s. 0937-0943. ISBN: 978-3-902734-11-2, ISSN: 1726-9679.

[7] PILAR, J. De Vido M, DIVOKY, M., MASON, P. D. Characterization of Bivoj/DiPOLE 100: HiLASE 100-J/10-Hz diode pumped solid state laser. In Solid State Lasers XXVII: Technology and Devices. San Francisco:2018, ISBN 9781510615076

[8] BHAMARE, S., RAMAKRISHMAN, S., MANNAVA, R., LANGER, K., VASUDEVAN, V. and QIAN, D. Simulationbased optimization of laser shock peening process for improved bending fatigue life of Ti-6Al-2Sn-4Zr-2Mo alloy. Surface \& Coatings Technology 232, pp.464-474, 2013. 